\title{
Chromium(VI) reduction and accumulation on the kaolinite surface in the presence of cationic soil flocculant
}

\author{
Katarzyna Szewczuk-Karpisz ${ }^{1} \cdot$ Gracja Fijałkowska $^{2} \cdot$ Małgorzata Wiśniewska $^{2} \cdot$ Grzegorz Wójcik $^{3}$
}

Received: 13 January 2020 / Accepted: 17 May 2020 / Published online: 30 May 2020

(C) The Author(s) 2020

\begin{abstract}
Purpose Heavy metal soluble forms pose a threat to plants, soil microflora, and microfauna. To limit their toxicity and mobility, various immobilizing additives are being developed. The main aim of the study was to determine the influence of soil flocculant (cationic polyacrylamide (CtPAM)) on the hexavalent chromium ion reduction and accumulation on the kaolinite surface. In this way, the efficiency of the selected polymer conditioner in the soil remediation was determined.

Materials and methods The adsorbed amounts of $\mathrm{Cr}(\mathrm{VI})$ and $\mathrm{CtPAM}$ on the kaolinite surface was determined spectrophotometrically (spectrophotometer UV/Vis) using specific indicators. The structure of electrical double layer formed on the kaolinite surface in the mixed system of cationic polyacrylamide and $\mathrm{Cr}(\mathrm{VI})$ ions was described based on the adsorptive measurements, zeta potential measurements, as well as potentiometric titration. The kaolinite aggregation in the presence of CtPAM and/or $\mathrm{Cr}(\mathrm{VI})$ ions was determined spectrophotometrically and proved using SEM microscopy. The reduction process of $\mathrm{Cr}(\mathrm{VI})$ to $\mathrm{Cr}(\mathrm{III})$ occurring in the adsorption layer was determined by diffuse reflectance spectroscopy (DRS).

Results and discussion The obtained results indicated that cationic polyacrylamide contributes to $\mathrm{Cr}$ (VI) reduction to $\mathrm{Cr}$ (III) form in the kaolinite suspension. This heavy metal ions are strongly adsorbed by the applied clay mineral, especially at pH 5 (then the $\mathrm{Cr}(\mathrm{VI})$-adsorbed amount equals $5.42 \mathrm{mg} / \mathrm{g}$ ). The $\mathrm{CtPAM}$ addition favors the $\mathrm{Cr}(\mathrm{VI})$ ion immobilization on the kaolinite surface. In the conditioner presence, the heavy metal-adsorbed amount is even at $7.34 \mathrm{mg} / \mathrm{g}$. The adsorption of CtPAM and chromium(VI) ions induces changes in the kaolinite surface charge density and electrokinetic potential. What is more, both substances favors the kaolinite aggregation.

Conclusions Cationic polyacrylamide may be considered a substance reducing the toxicity of chromium(VI) ions in the natural environment and decreasing their availability for soil organisms. It can improve the soil structure (by stimulating aggregation) and reduce environment pollution with heavy metals simultaneously.
\end{abstract}

Keywords $\mathrm{Cr}(\mathrm{VI})$ reduction $\cdot$ Soil flocculant adsorption $\cdot$ Kaolinite aggregation $\cdot$ Heavy metal ion immobilization $\cdot$ Mixed layer of PAM and $\mathrm{Cr}(\mathrm{VI})$

Responsible editor: Claudio Bini

Katarzyna Szewczuk-Karpisz

k.szewczuk-karpisz@ipan.lublin.pl

1 Institute of Agrophysics, Polish Academy of Sciences, Doświadczalna 4, 20-290 Lublin, Poland

2 Department of Radiochemistry and Environmental Chemistry, Institute of Chemical Sciences, Faculty of Chemistry, Maria Curie-Sklodowska University, M. Curie-Sklodowska Sq. 3, 20-031 Lublin, Poland

3 Department of Inorganic Chemistry, Institute of Chemical Sciences, Faculty of Chemistry, Maria Curie-Sklodowska University, M. Curie-Sklodowska Sq. 3, 20-031 Lublin, Poland

\section{Introduction}

Soil environment pollution with heavy metals is a threat to the proper functioning of organisms (Kilic et al. 2011). In contrast to pollution with organic compounds (such as aromatic hydrocarbons) heavy metals are not biodegradable and remain in the soil for thousands of years. They limit the number, activity, and biodiversity of microorganisms and plants (Alkorta et al. 2004). Most of heavy metals such as $\mathrm{Cr}, \mathrm{Pb}, \mathrm{Cd}$, and $\mathrm{Hg}$ have toxic effects on the organisms at minimal concentrations. The chromium toxicity depends on its oxidation stage. Chromium(VI) is much more hazardous than the chromium(III) one. $\mathrm{Cr}(\mathrm{VI})$ has a strong carcinogenic and 
mutagenic effects. It is considered as an allergenic factor which has high permeability through biological membranes and ability to oxidize unsaturated bonds in fatty acids, nucleic acids, and proteins (Vinutha et al. 2015; Hedberg et al. 2014; Dhal et al. 2013).

In response to the growing environment pollution, many remediation technologies for contaminated soils have been developed. One of them is immobilization (phytostabilization). This method involves the use of plants and various additives for stabilization of pollutants (Choppala et al. 2015; Borymski and Piotrowska-Seget 2014; AlMashqbeha et al. 2018). There are two types of immobilization: chemical and physical. They rely on metal ion binding and immobilizing based on covalent or ionic bonds as well as toxic forms capturing in complex polymer structures (Singh et al. 2012; Shi and Fernandez-Jimenez 2006; Hazrat et al. 2013; Ford and Neuman 2006; Weng et al. 2002). Materials used in such processes may be as follows: biochar, activated carbons, clay minerals, plant materials, polymers, and modern nanomaterials (Alkorta et al. 2004; Xiao et al. 2017; Roth et al. 2012; Fan et al. 2015). Owing to immobilization, the heavy metals uptake by plants and their leaching during surface runoff are reduced. This technique may be associated with sorption, ion exchange, redox processes, stable complex formation with organic matter, and their precipitation.

Toxic compound bioavailability depends mainly on their solubility in soil solution (Kwiatkowska-Malina and Maciejewska 2012; McLaughlin et al. 2000). Soluble forms are of particular importance because they pose a threat to plants, soil microflora, and microfauna. Soil organic matter content influences the substance solubility significantly (Ashworth and Alloway 2004; Cao et al. 2003; Xiao et al. 2017; Roth et al. 2012). Heavy metals associated with organic matter, mainly in the form of high-molecular organometallic complexes, are usually insoluble in water. Unfortunately, due to the constantly deteriorating soil condition, the organic matter content becomes lower and lower. What is more, soil acidification observed in many regions favors the mobility of toxic forms additionally. Thus, the study on innovative additives (e.g., clay minerals associated with polymers) that may immobilize heavy metals and reduce their bioavailability is of high importance. In the literature there is a lack of information about $\mathrm{Cr}(\mathrm{VI})$ mobility in the soil modified by flocculants.

Taking the above into consideration, the main aim of the study was to determine the influence of cationic polyacrylamide (CtPAM, soil flocculant) on the hexavalent chromium ion reduction and adsorption on the kaolinite surface. On the other hand, the $\mathrm{Cr}(\mathrm{VI})$ ion effect on the CtPAM-adsorbed amount on this mineral surface was also described. The structure of electrical double layer formed on the kaolinite surface in the presence of cationic polyacrylamide and/or $\mathrm{Cr}(\mathrm{VI})$ ions was studied using UV/Vis spectrophotometry, zeta potential measurements, as well as potentiometric titration. The kaolinite aggregation after the addition of cationic polymer and/or $\mathrm{Cr}(\mathrm{VI})$ ions was examined by spectrophotometric method and observed using SEM microscopy. The presented results provided information on sorption capacity of kaolinite relative to heavy metal ions and cationic polyacrylamide. It was examined whether the selected clay mineral may be used as soil additive which maintains its sorption capacity under specific environmental conditions (e.g., in the presence of soil flocculant). Performed experiments are part of the research on electrokinetic and adsorptive properties of various solids. Previous study concerned, inter alia, chromium(III) oxide adsorption capacity relative to anionic polyacrylamide (Wiśniewska et al. 2014b) and mixed flocculant (Wiśniewska et al. 2019).

\section{Experimental}

\subsection{Materials}

CtPAM (Korona), characterized by different contents of dissociable groups (35 or $80 \%$ of quaternary amine groups) with an average molecular weight equal to $7000 \mathrm{kDa}$, was used in the study. The CtPAM containing 35\% of ionizable groups was marked as CtPAM-35, whereas that containing $80 \%$ of ionizable groups - CtPAM- 80 . The $\mathrm{p} K_{\mathrm{b}}$ values of CtPAM-35 and CtPAM- 80 equal 9.3 and 9.5 , respectively. The dissociation degrees of cationic groups present in the polymer macromolecules are 99.9\% (at pH 5) and 99.4-99.6\% (at pH 7).

Kaolinite (Sigma-Aldrich) - a clay mineral belonging to the aluminosilicates, was used as an adsorbent. It has a 1:1 structure, in which tetrahedrons of silica and octahedrons of alumina form layers. The $\mathrm{SiO}_{4}$ and $\mathrm{Al}(\mathrm{OH})_{6}$ sheets are bonded together by shared common plane of oxygen atoms or hydrogen bonds. The specific surface area $\left(S_{\mathrm{BET}}\right)$ and porosity of kaolinite were determined using the nitrogen adsorption/ desorption isotherm method (Micromeritics ASAP 2020 analyzer). The elemental composition of kaolinite was obtained by means of XRF technique (Panalytical ED-XRF type Epsilon 3 spectrometer). Surface functional groups of kaolinite was determined using the Fourier-transform infrared spectroscopy (FTIR spectrometer, Nicolet 8700A, Thermo Scientific).

\subsection{Methods}

All experiments were performed at $25^{\circ} \mathrm{C}$ in the presence of $\mathrm{NaCl}$ (with concentration $0.001 \mathrm{~mol} / \mathrm{dm}^{3}$ ) as a supporting electrolyte.

Adsorption measurements were carried out at $\mathrm{pH} 5$ and 7 (common $\mathrm{pH}$ values of cultivated soils). The $\mathrm{Cr}(\mathrm{VI})$ - or CtPAM-adsorbed amount on the kaolinite surface was determined based on the concentration changes in the solution 
noted after the adsorption. The $\mathrm{Cr}(\mathrm{VI})$ and CtPAM concentrations were established spectrophotometrically (spectrophotometer UV/Vis Carry 1000, Varian). In the case of chromium(VI) ions, the reaction with diphenylcarbazide (Gardner and Comber 2002) was used, whereas in the case of CtPAM, the procedure with brilliant yellow in alkaline environment ( $\mathrm{pH}$ 9) was applied. The suspensions were prepared using $0.1 \mathrm{~g}$ of the solid (per $10 \mathrm{~cm}^{3}$ of the solution). The $\mathrm{Cr}(\mathrm{VI})$ ion concentration in the probes was in the range of 1$200 \mathrm{ppm}$, in turn the CtPAM one-20-200 ppm. The adsorption was conducted for $24 \mathrm{~h}$ under shaking conditions (250 rpm). After its completion, the samples were centrifuged and the $\mathrm{Cr}(\mathrm{VI}) / \mathrm{CtPAM}$ concentration was established in the obtained supernatants. The obtained data were fitted to selected theoretical models, i.e., Langmuir (Eq. 1) and Freundlich (Eq. 2) (Ościk 1969; Foo and Hameed 2010):

$q_{\mathrm{e}}=\frac{q_{\mathrm{m}} K_{\mathrm{L}} C_{\mathrm{e}}}{1+K_{\mathrm{L}} C_{\mathrm{e}}}$

$q_{\mathrm{e}}=K_{\mathrm{F}} C_{\mathrm{e}}^{1 / n}$

where $K_{\mathrm{F}}\left(\mathrm{mg} / \mathrm{g}(\mathrm{mg} / \mathrm{L})^{-1 / n \mathrm{~F}}\right)$ is the Freundlich parameter, $K_{\mathrm{L}}(\mathrm{L} / \mathrm{mg})$ is the Langmuir parameter, $q_{\mathrm{e}}(\mathrm{mg} / \mathrm{g})$ is the equilibrium adsorption capacity, $C_{\mathrm{e}}$ is the equilibrium liquid phase concentration (ppm), $q_{\mathrm{m}}$ is the maximum adsorption capacity in Langmuir model $(\mathrm{mg} / \mathrm{g})$, and $n$ is the Freundlich constant related to adsorption intensity.

Kinetics of $\mathrm{Cr}(\mathrm{VI})$ and $\mathrm{CtPAM}$ adsorption on the kaolinite surface were also examined. These measurements were performed at $\mathrm{pH} 5$, using $100 \mathrm{ppm}$ of CtPAM or $5 \mathrm{ppm}$ of $\mathrm{Cr}(\mathrm{VI})$ ions. The kaolinite weight in the suspensions was $0.1 \mathrm{~g}$ (per 10 $\mathrm{cm}^{3}$ of the solution). After the samples preparation and the $\mathrm{pH}$ adjustment, the adsorption was conducted for 5, 10, 20, 30, $40,50,60,90,120$, and 180 min under shaking conditions. After the process completion, the suspensions were centrifuged and the $\mathrm{Cr}(\mathrm{VI})$ ions or CtPAM concentration was established in the obtained solutions. The kinetics results were fitted to the pseudo-first-order (Eq. 3) and pseudo-secondorder equations (Eq. 4) (Ho and McKay 1998; Ho and McKay 2002):

$\frac{\mathrm{d} q_{t}}{\mathrm{~d} t}=k_{2}\left(q_{\mathrm{e}}-q_{\mathrm{t}}\right)$

$\frac{\mathrm{d} q_{t}}{\mathrm{~d} t}=k_{2}\left(q_{\mathrm{e}}-q_{\mathrm{t}}\right)^{2}$

where $q_{\mathrm{e}}$ is the adsorbed amount at equilibrium ( $\left.\mathrm{mg} / \mathrm{g}\right), q_{\mathrm{t}}$ is the adsorbed amount after time " $t$ " (mg/g), and $k_{1}(1 / \mathrm{min})$ and $k_{2}\left(\mathrm{~g} /\left(\mathrm{mg}^{*} \mathrm{~min}\right)\right.$ are the equilibrium rate constants.

The surface charge density $\left(\sigma_{0}\right)$ of kaolinite in the absence and presence of cationic polyacrylamide and/or $\mathrm{Cr}(\mathrm{VI})$ ions was determined using the potentiometric titration method, which was carried out applying an automated set co-working with the Titr_v3 software (Janusz 1994). A single titration was performed in the $\mathrm{pH}$ range of $3-11$. The suspensions (with a volume of $50 \mathrm{~cm}^{3}$ ) were prepared using $2.5 \mathrm{~g}$ of kaolinite. The $\mathrm{Cr}(\mathrm{VI})$ ion concentration was $1 \mathrm{ppm}$, whereas the CtPAM one-100 ppm.

The electrophoretic mobility of the kaolinite particles dispersed in the solution non-containing and containing polyacrylamide and/or $\mathrm{Cr}(\mathrm{VI})$ ions was measured using the zetasizer Nano ZS (Malvern Instruments). At first, $100 \mathrm{~cm}^{3}$ of the suspension was prepared using $0.1 \mathrm{~g}$ of kaolinite. Then, the system was sonicated for $3 \mathrm{~min}$ and divided into several parts, in which different $\mathrm{pH}$ values were adjusted (changing in the range 3-9). Based on the measured electrophoretic mobility values, the electrokinetic potential $(\zeta)$ was calculated using a special software and Henry's equation (Ohshima 1994).

The reduction process of $\mathrm{Cr}(\mathrm{VI})$ to $\mathrm{Cr}(\mathrm{III})$ occurring in the CtPAM adsorption layer was determined by diffuse reflectance spectroscopy (DRS). The DRS spectra were measured using the Jasco V-660 spectrometer equipped with diffuse reflectance attachment PIV-756 (Jasco, Japan). After the adsorption process, the solid samples were centrifuged, dried, and exposed to the UV-Vis beam. The deconvolution procedure of the obtained spectra was applied to separate the signals coming from various forms of chromium.

The changes in the soil suspension stability without and with CtPAM and/or Cr(VI) ions was monitored using spectrophotometry method (spectrophotometer Carry 1000, Varian). The absorbance of clay mineral suspension was measured over time at a wavelength equal to $500 \mathrm{~nm}$. The cationic polyacrylamide concentration in the examined systems was $100 \mathrm{ppm}$, in turn the $\mathrm{Cr}(\mathrm{VI})$ ion one- $-1 \mathrm{ppm}$. The kaolinite aggregation was also observed using SEM microscope (Quanta 3D FEG, FEI Company).

The electrokinetic mobility, stability, and surface charge density measurements were performed three times for a given system. The measurement error did not exceed 2-3\%, and therefore, error bars were not added to the result diagrams. Adsorption measurements (adsorption kinetics and isotherms) were also performed three times for the selected system. The measurement error was larger-about 5-6\%, and thus error bars were added to the diagrams.

\section{Results and discussion}

\subsection{Kaolinite characteristics}

Based on the obtained nitrogen adsorption/desorption isotherms, it was stated that specific surface area $\left(S_{\mathrm{BET}}\right)$ of kaolinite equals to $8.02 \mathrm{~m}^{2} / \mathrm{g}$. The mineral contains two groups of mesopores of the following average diameters, 3.8 and 11.7 $\mathrm{nm}$. The XRF measurements indicated that kaolinite was composed of $\mathrm{Si}$ (22.2 wt \%), Al (19.6 wt\%), K (1.5 wt \%), Fe 
(0.337 wt \%), and $\mathrm{P}(0.189 \mathrm{wt} \%)$ and trace elements such as $\mathrm{Na}, \mathrm{Mg}, \mathrm{Cr}, \mathrm{Rb}$, or $\mathrm{Zn}$.

The FTIR analysis showed the specific functional groups of the examined kaolinite. The obtained spectrum, presented in Fig. 1, contains the bands corresponding with: (1) the Si-O stretching vibrations $\left(429,469\right.$, and $\left.597 \mathrm{~cm}^{-1}\right),(2)$ the $\mathrm{Mg} / \mathrm{Al}-$ $\mathrm{OH}$ vibrations $\left(698 \mathrm{~cm}^{-1}\right),(3)$ the $\mathrm{Si}-\mathrm{O}-\mathrm{Al}$ group deformation (765 and $796 \mathrm{~cm}^{-1}$ ), (4) the $\mathrm{OH}$ bending vibrations of $\mathrm{Al}-\mathrm{OH}$ $\left(911 \mathrm{~cm}^{-1}\right),(5)$ the $\mathrm{Si}-\mathrm{O}$ stretching vibrations (1006, 1030, and $1114 \mathrm{~cm}^{-1}$ ) (Gild et al. 2017; Tironi et al. 2012; Ogundiran and Winjobi 2015). The four bands present at $3619,3651,3671$, and $3696 \mathrm{~cm}^{-1}$ corresponds with the stretching of $\mathrm{OH}$ groups. They are well defined, which confirmed that the kaolinite structure is ordered (Bich et al. 2009).

The $\sigma_{0}$ and zeta potential ( $\zeta$ ) of kaolinite in the supporting electrolyte solution are presented in Fig. 2. The obtained results showed that both $\sigma_{0}$ and $\zeta$ parameters depend strictly on the solution $\mathrm{pH}$. When the $\mathrm{pH}$ value increases, the surface charge density of kaolinite reaches more negative values. It is connected with dissociation of functional groups present on the mineral surface. The $\mathrm{pH}_{\mathrm{pzc}}$ (point of the zero charge) of kaolinite equals 3.37. At this $\mathrm{pH}$ value, the concentrations of positively and negatively charged surface groups are identical. The obtained $\mathrm{pH}_{\mathrm{pzc}}$ parameter is consistent with the literature reports (Yukselen-Aksoy and Kaya 2003). Electrokinetic potential of kaolinite in the supporting electrolyte solution assumes only negative values in the whole studied $\mathrm{pH}$ range. What is more, the absolute values of negative zeta potential become higher and higher when the system $\mathrm{pH}$ increases. The obtained data indicated that the isoelectric point $\left(\mathrm{pH}_{\mathrm{iep}}\right)$ of kaolinite assumes the value lower than 3. According to the literature, $\mathrm{pH}_{\text {iep }}$ of kaolinite is in the range of 2.8-4 (Ndlovu et al. 2015).

\section{2 $\mathrm{Cr}(\mathrm{VI})$ ions adsorption on the kaolinite surface and its effect on the solid $\sigma_{0}$ and $\zeta$ parameters}

Figure 3 a presents the kinetics of $\mathrm{Cr}(\mathrm{VI})$ ion adsorption on the kaolinite surface at $\mathrm{pH} 5$. The obtained results showed that the

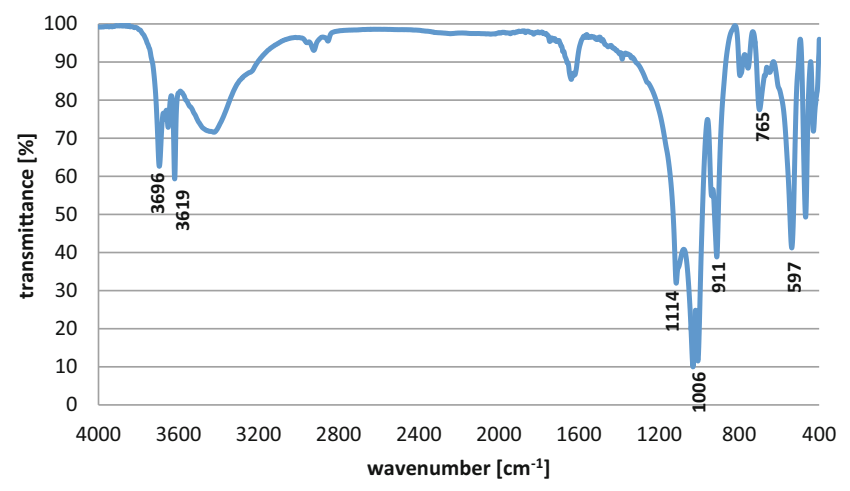

Fig. 1 FTIR spectrum of kaolinite

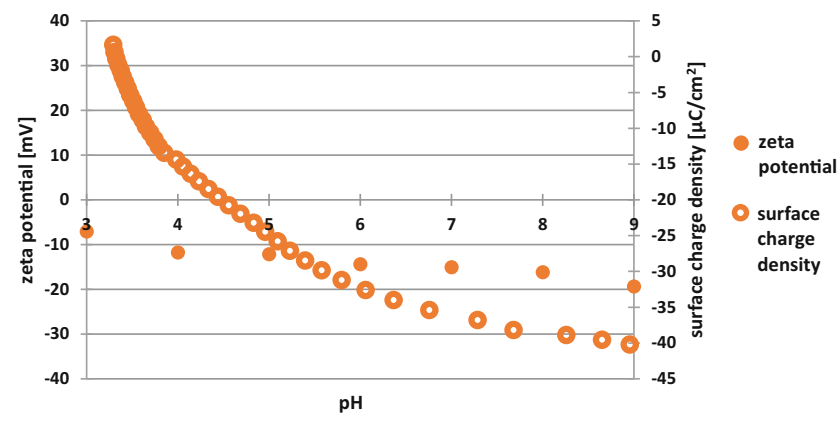

Fig. 2 Surface charge density (open points) and zeta potential (solid points) of kaolinite in the supporting electrolyte solution

system reaches the equilibrium state after $50 \mathrm{~min}$. After this time, the adsorbed amount of heavy metal ions on the kaolinite surface does not change. The obtained results were fitted to the pseudo-second-order model with $R^{2}$ value equal to 0.963 (Table 1). This indicates that $\mathrm{Cr}(\mathrm{VI})$ adsorption involves chemisorption (Wang et al. 2007).

Figure $3 \mathrm{~b}$ shows the $\mathrm{Cr}(\mathrm{VI})$ adsorption isotherms on the mineral surface obtained at $\mathrm{pH} 5$ and 7 . These results were fitted to Langmuir and Freundlich models (Table 2). The best fitting was obtained for Langmuir model $-R^{2}$ is 0.953 at $\mathrm{pH} 5$ and 0.994 at $\mathrm{pH}$ 7. This means that chromium(VI) ions form a monolayer on the kaolinite surface during the adsorption.
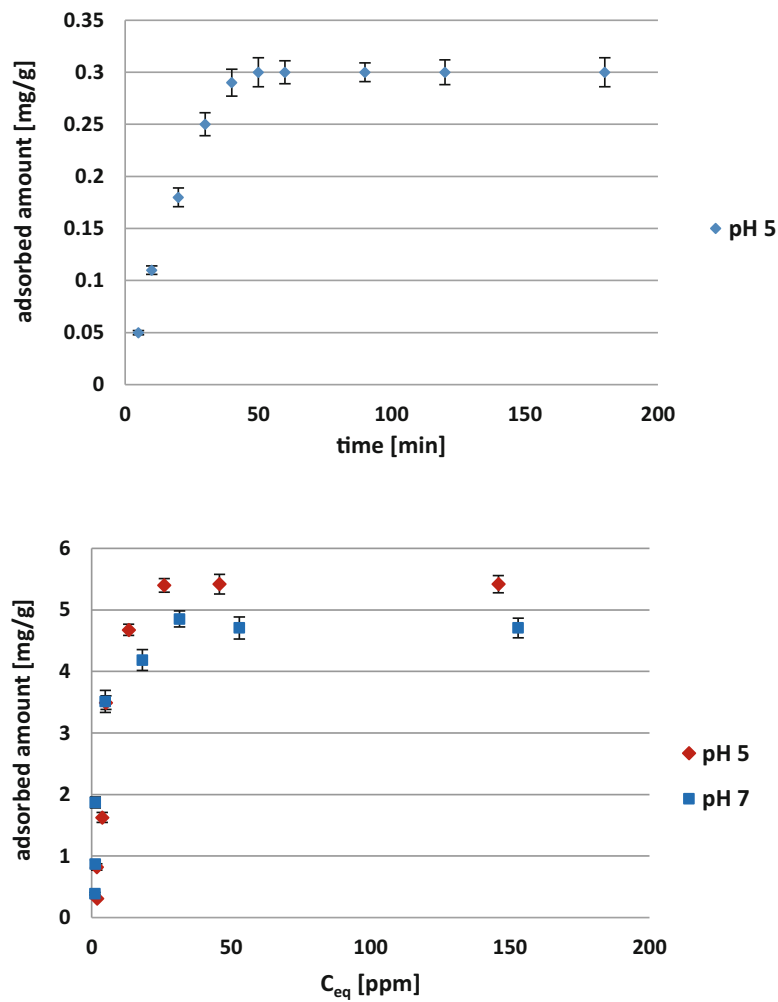

b)

Fig. 3 Chromium(VI) ions adsorbed amount (a) and adsorption kinetics (b) on the kaolinite surface 
Table 1 Kinetics parameters acquired from pseudo-first- and pseudo-second-order models of $\mathrm{Cr}(\mathrm{VI})$ ion adsorption on the kaolinite surface at $\mathrm{pH} 5$

\begin{tabular}{|c|c|c|c|c|c|c|}
\hline & \multicolumn{6}{|l|}{ Model } \\
\hline & \multicolumn{3}{|c|}{ Pseudo-first-order } & \multicolumn{3}{|c|}{ Pseudo-second-order } \\
\hline & $q_{\mathrm{e}}(\mathrm{mg} / \mathrm{g})$ & $k_{1}(1 / \min )$ & $R^{2}$ & $q_{\mathrm{e}}(\mathrm{mg} / \mathrm{g})$ & $k_{2}(\mathrm{~g} /(\mathrm{mg} * \min ))$ & $R^{2}$ \\
\hline Kinetics parameters & 1.018 & 5.437 & 0.544 & 0.369 & 0.138 & 0.963 \\
\hline
\end{tabular}

Moreover, the adsorption energy distribution in the formed monolayer is uniform (Ościk 1969). In aqueous solutions, chromium occurs in various species depending on the $\mathrm{pH}$ value. In the examined $\mathrm{pH}$ range (3-9), the most stable forms of this heavy metal are $\mathrm{HCrO}_{4}{ }^{-}$and $\mathrm{CrO}_{4}{ }^{2-}$ anions (Weng et al. 2008; Fijałkowski et al. 2012). Due to higher values of negative surface charge of the mineral at $\mathrm{pH} 7$, the affinity of chromium(VI) ions to the kaolinite surface is lower under these conditions (compared to $\mathrm{pH} 5$ ). The $\sigma_{0}$ parameter of kaolinite is about $-9 \mu \mathrm{C} / \mathrm{cm}^{2}$ at $\mathrm{pH} 5$ and $-33 \mu \mathrm{C} / \mathrm{cm}^{2}$ at $\mathrm{pH} 7$. At $\mathrm{pH} 5$, for the initial chromium(VI) ion concentration equal to $100 \mathrm{ppm}$, their adsorbed amount on the kaolinite surface was equal to $5.42 \mathrm{mg} / \mathrm{g}$, which means that the examined mineral adsorbs $54.2 \%$ of the heavy metal ions. In turn at $\mathrm{pH} 7$, for the same initial concentration, the $\mathrm{Cr}(\mathrm{VI})$-adsorbed amount was $4.71 \mathrm{mg} / \mathrm{g}$, which indicated that $47.1 \%$ of the ions are adsorbed.

In Figs. 4 and 5, the surface charge density and zeta potential of the kaolinite particles without and with hexavalent chromium ions are presented. The addition of $\mathrm{Cr}$ ions to the system causes significant changes in the $\sigma_{0}$ and $\zeta$ parameters. The negative electrokinetic potential of the mineral in the heavy metal presence has higher absolute values than that observed in the supporting electrolyte solution. This is probably caused by the presence of inorganic anions in the slipping plane area formed around kaolinite particles. The changes in surface charge density of kaolinite after the $\mathrm{Cr}(\mathrm{VI})$ addition were also observed (Fig. 5). The decrease in the negative $\sigma_{0}$ values in the chromium anion presence was noted in the whole examined $\mathrm{pH}$ range (3-9). Based on the site-binding model (Wiśniewska et al. 2017), the above phenomenon is associated with interaction of chromium(VI) ions with the kaolinite surface groups resulting in the creation of additional number of positively charged surface sites.

\subsection{Cationic polyacrylamide adsorption on the kaolinite surface and its effect on the solid $\sigma_{0}$ and $\zeta$ parameters}

The cationic polyacrylamide adsorption kinetics on the kaolinite surface are presented in Fig. 6a. Based on these results, it can be stated that the examined systems containing CtPAM (CtPAM-35 or CtPAM-80) reach equilibrium after $1 \mathrm{~h}$. The kinetics results were the best fitted to the pseudo-second-order model. $R^{2}$ was 0.964 for CtPAM-35 and 0.978 for CtPAM-80 (Table 3).

The polymer-adsorbed amounts on the kaolinite surface obtained at pH 5 and 7 are presented in Fig. 6b. The CtPAM adsorption on the kaolinite surface is the result of several interactions: compensation or neutralization of solid surface charge, solid-polymer complexes creation, and hydrogen bridges formation. At the examined $\mathrm{pH}$ values (5 and 7), cationic polyacrylamide has expanded conformation due to high dissociation degree value (over 99\%). The electrostatic repulsion occurs between CtPAM functional groups and, owing to it, the polymer segments are spaced apart. The examined cationic polyacrylamide samples differs in the dissociable group content, i.e., CtPAM-35 contains $35 \%$ of quaternary amine groups, whereas CtPAM-80-80\% ones. When these groups undergo dissociation, the polymeric chains are positively charged (the $-\mathrm{N}\left(\mathrm{CH}_{3}\right)_{3}{ }^{+}$groups are present in the macromolecules). Therefore, the CtPAM adsorption on the kaolinite surface is mainly affected by the electrostatic attraction between dissociated hydroxyl groups of the solid $\left(-\mathrm{SO}^{-}\right)$and positively charged polymer moieties. The affinity of cationic macromolecules to the negatively charged kaolinite is stronger for the polymer containing higher number of positively charged groups. At $\mathrm{pH} 5$, the CtPAM-35 adsorbed amount equals $2.31 \mathrm{mg} / \mathrm{g}$, whereas the CtPAM-80 one- $3.05 \mathrm{mg} / \mathrm{g}$.
Table 2 Langmuir and Freundlich isotherm parameters for $\mathrm{Cr}(\mathrm{VI})$ ion adsorption on the kaolinite surface

\begin{tabular}{|c|c|c|c|c|c|c|}
\hline \multirow[t]{3}{*}{ Isotherm parameters } & \multicolumn{6}{|l|}{ Model } \\
\hline & \multicolumn{3}{|l|}{ Langmuir } & \multicolumn{3}{|c|}{ Freundlich } \\
\hline & $q_{\mathrm{m}}(\mathrm{mg} / \mathrm{g})$ & $K_{\mathrm{L}}(\mathrm{L} / \mathrm{mg})$ & $R^{2}$ & $n$ & $K_{\mathrm{F}}\left(\mathrm{mg} / \mathrm{g}(\mathrm{mg} / \mathrm{L})^{-1 / n \mathrm{~F}}\right)$ & $R^{2}$ \\
\hline pH 5 & 5.963 & 0.059 & 0.953 & 1.805 & 0.12 & 0.6678 \\
\hline pH 7 & 4.895 & 0.231 & 0.994 & 2.453 & 0.158 & 0.675 \\
\hline
\end{tabular}


Fig. 4 Zeta potential of kaolinite in the absence and presence of $\mathrm{Cr}(\mathrm{VI})$ ions and/or cationic polyacrylamide

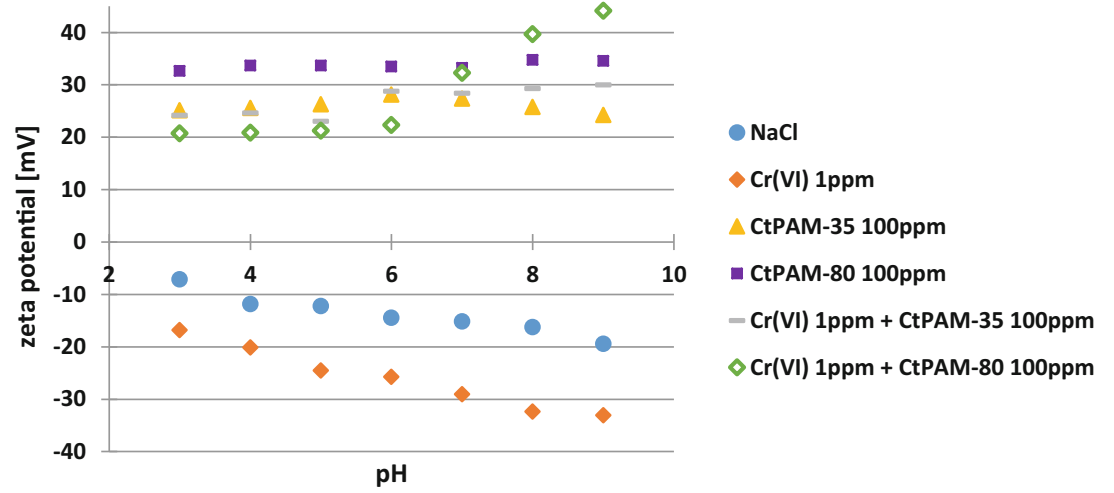

At $\mathrm{pH}$ 7, the observed polymer-adsorbed amounts were slightly higher. They were $2.91 \mathrm{mg} / \mathrm{g}$ of CtPAM-35 and $3.37 \mathrm{mg} / \mathrm{g}$ of CtPAM-80. This phenomenon is dictated by stronger electrostatic attraction between adsorbate and adsorbent at higher $\mathrm{pH}$ value (the negative solid surface charge is higher).

The electrokinetic properties of the kaolinite/supporting electrolyte/CtPAM system are presented in Figs. 4 and 5. The addition of both cationic polymers to the suspension changes the surface charge density and zeta potential of the examined aluminosilicate. Electrokinetic potential of the solid assumes only positive values in the whole $\mathrm{pH}$ range. This is due to the presence of positively charged groups of the polymer in the slipping plane area. The absolute values of surface charge of kaolinite after the CtPAM addition are lower than those observed without the polymer. This effect is induced by positively charged moieties of "loop" and "tail" structures of the adsorbed macromolecules located in by-surface layer. The polymer with higher content of dissociable amine groups (CtPAM-80) has a stronger impact on the $\sigma_{0}$ and $\zeta$ valueslarger changes in these parameters are noted (Wiśniewska et al. 2014a).

\section{4 $\mathrm{Cr}(\mathrm{VI})$ and cationic polyacrylamide adsorption on the kaolinite surface in the mixed systems}

The $\mathrm{Cr}(\mathrm{VI})$ ion influence on the cationic polyacrylamide adsorption on the kaolinite surface at $\mathrm{pH} 5$ and 7 is presented in
Table 4. Heavy metal ions affect both CtPAM-35 and CtPAM-80 adsorbed amounts. In the experiments the concentrations of both the polymer and $\mathrm{Cr}(\mathrm{VI})$ ions were $100 \mathrm{ppm}$. Both adsorbates were added to the studied suspensions simultaneously or at the time interval of $1 \mathrm{~h}$. Based on the obtained results, it can be stated that the chromium(VI) ions strongly determine the polymer-adsorbed amount on the kaolinite surface. When $\mathrm{Cr}(\mathrm{VI})$ ions were added after $1 \mathrm{~h}$, the polymeradsorbed amount is twice higher (compared with the system without heavy metal ions). This dependence is observed for both CtPAM-35 and CtPAM-80. When the adsorbates are added at the same time, the CtPAM-adsorbed amount increase is also clear. These observations can be related to the interaction between inorganic anions $\left(\mathrm{HCrO}_{4}^{-}\right.$and $\left.\mathrm{CrO}_{4}{ }^{2-}\right)$ and positively charged macromolecules (containing $-\mathrm{N}\left(\mathrm{CH}_{3}\right)_{3}{ }^{+}$ groups). As a result, the formation of polymer-metal ion complexes occurs. Hydrogen bond creation between neutral undissociated amide groups of the polymer and chromium anions may also take place. What is more, the adsorbed polyacrylamide chains can capture heavy metal ions from the solution by hydrogen bridge formation.

Chromium(VI) ion-adsorbed amount on the kaolinite surface is strictly dependent on the CtPAM presence. The obtained results are presented in Table 5. The noticeable increase in the chromium(VI) adsorption was obtained. A slightly higher $\mathrm{Cr}(\mathrm{VI})$-adsorbed amount was observed when the polymer was added firstly to the kaolinite suspension. Similarly to the
Fig. 5 Surface charge density $\left(\sigma_{0}\right)$ of kaolinite in the absence and presence of $\mathrm{Cr}(\mathrm{VI})$ ions and/ or cationic polyacrylamide

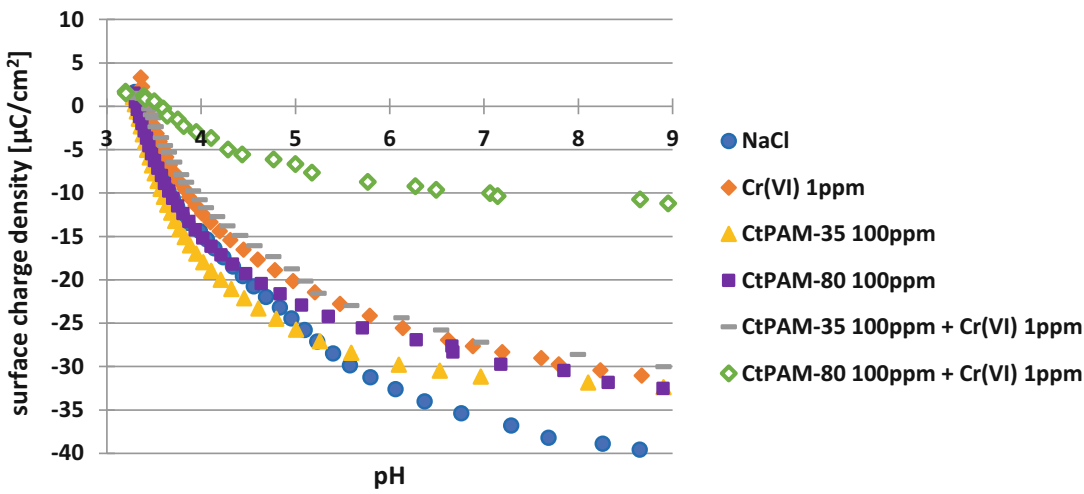




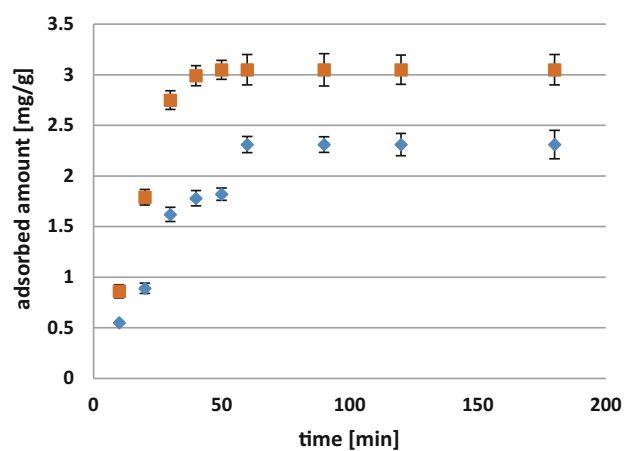

- CtPAM-35

CtPAM-80

a)

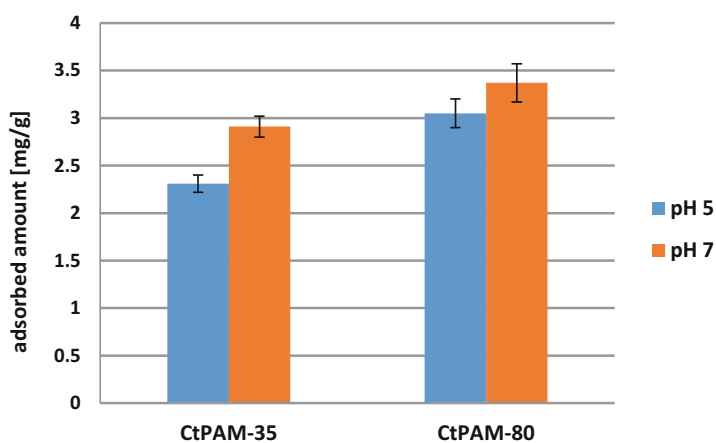

b)

Fig. 6 Cationic polyacrylamide adsorption size (a) and kinetics (b) on the kaolinite surface

cationic PAM adsorption, due to interaction between opposite charged adsorbates, the heavy metal-polymer complexes are probably formed. Besides, negatively charged chromium(VI) ions have higher affinity to the kaolinite surface modified by polyacrylamide macromolecules containing positively charged moieties. This indicates that cationic polyacrylamide may be considered a substance favoring the chromium(VI) ion immobilization on the kaolinite surface.

Electrokinetic potential of kaolinite in the presence of CtPAM and $\mathrm{Cr}(\mathrm{VI})$ ions assumes positive values. During the adsorption, the formed polymer-chromium(VI) ion complexes have such conformation that positively charged polymer groups are located in the slipping plane area of electrical double layer. They contribute to the described changes in the kaolinite zeta potential. On the other hand, the absolute values of surface charge of the mineral are lower after $\mathrm{Cr}$ (VI)/CtPAM addition (compared with the values noted without adsorbates).
Table 4 CtPAM-adsorbed amount on the kaolinite surface in the mixed $\mathrm{Cr}(\mathrm{VI}) / \mathrm{CtPAM}$ systems (Cr(VI) and CtPAM initial concentrations were equal to $100 \mathrm{ppm})$

\begin{tabular}{lll}
\hline Adsorbates addition order & $\mathrm{pH} \mathrm{5}$ & $\mathrm{pH} 7$ \\
\hline$\Gamma_{\text {CtPAM-35 }}(\mathrm{mg} / \mathrm{g})$ & & \\
CtPAM-35 alone & 2.31 & 2.91 \\
CtPAM-35 + Cr(VI) together & 4.7 & 5.2 \\
CtPAM-35 + Cr(VI) after 1 h & 5.9 & 6.1 \\
Cr(VI) + CtPAM-35 after 1 h & 5.4 & 5.2 \\
$\Gamma_{\text {CtPAM-80 }(\mathrm{mg} / \mathrm{g})}$ & & \\
CtPAM-80 alone & 3.05 & 3.37 \\
CtPAM + Cr(VI) together & 5.2 & 5.4 \\
CtPAM + Cr(VI) after 1 h & 6.2 & 6.5 \\
Cr(VI) + CtPAM after 1 h & 5.9 & 6.1 \\
\hline
\end{tabular}

This is associated with the presence of CtPAM-positive groups in the non-adsorbed segments of the heavy metalpolymer complexes.

\subsection{Cationic polyacrylamide influence on $\mathrm{Cr}(\mathrm{VI})$ reduction}

Figure 7 presents the DRS spectra obtained in the kaolinite/ cationic polyacrylamide/chromium(VI) ion system. They indicated that in the cationic polymer presence there is a clear reduction of chromium(VI) to chromium(III) in the mixed adsorption layer formed on the kaolinite surface. The peak corresponding with chromium(III) ions is visible in the diagram. The free electron pair located on the nitrogen atom of the polymeric amide group is involved in the described process. The $\mathrm{Cr}(\mathrm{VI})$ reduction to $\mathrm{Cr}$ (III) is highly desirable in environment protection because this process decreases the chromium toxicity for organisms.

\section{$3.6 \mathrm{Cr}(\mathrm{VI})$ and cationic polyacrylamide impact on kaolinite aggregation}

The stability of examined kaolinite suspension in the absence and presence of $\mathrm{CtPAM} / \mathrm{Cr}(\mathrm{VI})$ ions is presented in Fig. 8. The system without any additives are more stable
Table 3 Kinetics parameters acquired from pseudo-first- and pseudo-second-order models of cationic polyacrylamide adsorption on the kaolinite surface at pH 5

\begin{tabular}{|c|c|c|c|c|c|c|}
\hline \multirow[t]{3}{*}{ Kinetics parameters } & \multicolumn{6}{|l|}{ Model } \\
\hline & \multicolumn{3}{|c|}{ Pseudo-first-order } & \multicolumn{3}{|c|}{ Pseudo-second-order } \\
\hline & $q_{\mathrm{e}}(\mathrm{mg} / \mathrm{g})$ & $k_{1}(1 / \min )$ & $R^{2}$ & $q_{\mathrm{e}}(\mathrm{mg} / \mathrm{g})$ & $k_{2}(\mathrm{~g} /(\mathrm{mg} * \mathrm{~min}))$ & $R^{2}$ \\
\hline CtPAM-35 & 1.042 & 0.638 & 0.663 & 2.816 & 0.012 & 0.964 \\
\hline CtPAM-80 & 1.046 & 2.641 & 0.535 & 3.364 & 0.024 & 0.978 \\
\hline
\end{tabular}


Table $5 \mathrm{Cr}(\mathrm{VI})$-adsorbed amount on the kaolinite surface in the mixed $\mathrm{Cr}(\mathrm{VI}) / \mathrm{CtPAM}$ systems (Cr(VI) and CtPAM initial concentrations were equal to $100 \mathrm{ppm})$

\begin{tabular}{lll}
\hline Adsorbates addition order & $\mathrm{pH} \mathrm{5}$ & $\mathrm{pH} \mathrm{7}$ \\
\hline$\Gamma_{\mathrm{Cr}(\mathrm{VI})}(\mathrm{mg} / \mathrm{g})$ & & \\
Cr(VI) alone & 5.42 & 4.71 \\
CtPAM-30 + Cr(VI) together & 6.25 & 6.1 \\
CtPAM-30 + Cr(VI) after 1 h & 6.93 & 6.68 \\
Cr(VI) + CtPAM-30 after 1 h & 6.64 & 6.52 \\
$\Gamma_{\mathrm{Cr}(\mathrm{VI})}(\mathrm{mg} / \mathrm{g})$ & & \\
$\mathrm{Cr}(\mathrm{VI})$ alone & 5.42 & 4.71 \\
$\mathrm{CtPAM}-80+\mathrm{Cr}(\mathrm{VI})$ together & 6.7 & 6.63 \\
$\mathrm{CtPAM}-80+\mathrm{Cr}(\mathrm{VI})$ after $1 \mathrm{~h}$ & 7.34 & 7.19 \\
$\mathrm{Cr}(\mathrm{VI})+\mathrm{CtPAM}-80$ after $1 \mathrm{~h}$ & 7.07 & 6.94 \\
\hline
\end{tabular}

at $\mathrm{pH} 7$ (the absorbance changes over time are slower), which is mainly connected with higher absolute values of zeta potential. The polymer addition (without or with chromium(VI) ions) changes the system stability-a significant reduction is observed both at $\mathrm{pH} 5$ and 7 . The absorbance decreases over time rapidly and remains at low level. Due to interaction between kaolinite surface groups and CtPAM moieties, the creation of large aggregates occurs. In the presence of $\mathrm{Cr}(\mathrm{VI})$, the kaolinite/ CtPAM suspension becomes more unstable in comparison with those without heavy metal ions. This effect is greater for CtPAM- 80 because in such a case the polymer-metal ion complexes are effectively formed and adsorbed on the solid particle surface, causing more efficient flocculation.

In Fig. 9, the SEM images of kaolinite particles in the presence and absence of cationic flocculant are presented. They also showed the solid aggregation process. There is a formation of flocs consisting of kaolinite particles covered with the CtPAM layers.

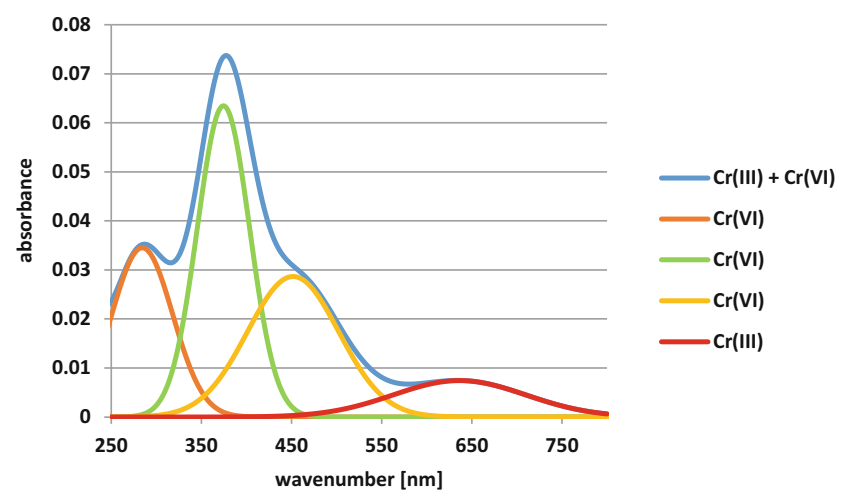

Fig. 7 DRS spectra obtained in the kaolinite/cationic polyacrylamide/ chromium(VI) ion system

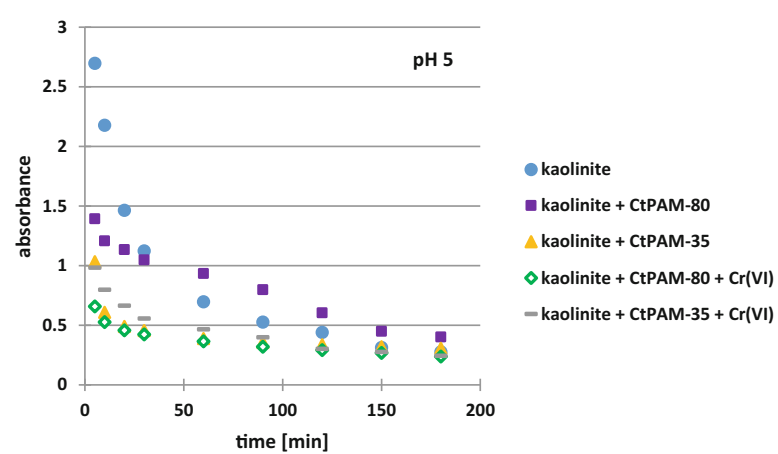

a)

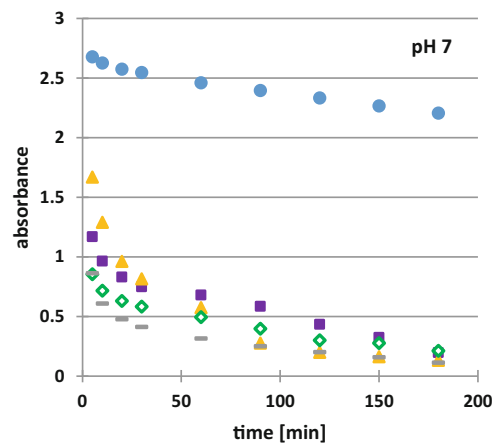

kaolinite

vaolinite + CtPAM-80

$\triangle$ kaolinite + CtPAM-35

$\checkmark$ kaolinite + CtPAM-80 $+\mathrm{Cr}(\mathrm{VI})$

- kaolinite + CtPAM-35 + Cr(VI)

b)

Fig. 8 Stability changes of the kaolinite suspension in absence and presence of $\mathrm{Cr}(\mathrm{VI})$ ions and/or cationic polyacrylamide at $\mathrm{pH} 5$ (a) and pH 7 (b)

\section{Conclusions}

Based on the obtained results, the following conclusions can be drawn:

(1) The adsorption of both CtPAM forms and chromium(VI) ions induces changes in the kaolinite surface charge density and electrokinetic potential (and also in the structure of electrical double layer of the mineral particles).

(2) Cationic polyacrylamide adsorbs on the kaolinite surface. The CtPAM affinity to the mineral surface increases when the content of positively charged groups in the macromolecules as well as the $\mathrm{pH}$ value are higher.

(3) Chromium(VI) ions are adsorbed on the kaolinite surface both at $\mathrm{pH} 5$ and 7 . When the $\mathrm{pH}$ value is lower, the larger adsorption capacity of the solid relative to $\mathrm{Cr}(\mathrm{VI})$ ions is observed.

(4) Chromium(VI) ions favors the CtPAM adsorption on the kaolinite surface. Similarly, cationic polymer induces the $\mathrm{Cr}(\mathrm{VI})$ adsorption on the solid surface. These phenomena are associated with the polymer-heavy metal ion complex formation.

(5) Cationic polyacrylamide causes the $\mathrm{Cr}(\mathrm{VI})$ reduction to the $\mathrm{Cr}$ (III) form in the mixed adsorption layer.

(6) CtPAM presence (and also $\mathrm{Cr}(\mathrm{VI})$ ions in the mixed system) contributes to strong kaolinite aggregation. 
Fig. 9 SEM images of the kaolinite particles without (a) and with (b) cationic polyacrylamide
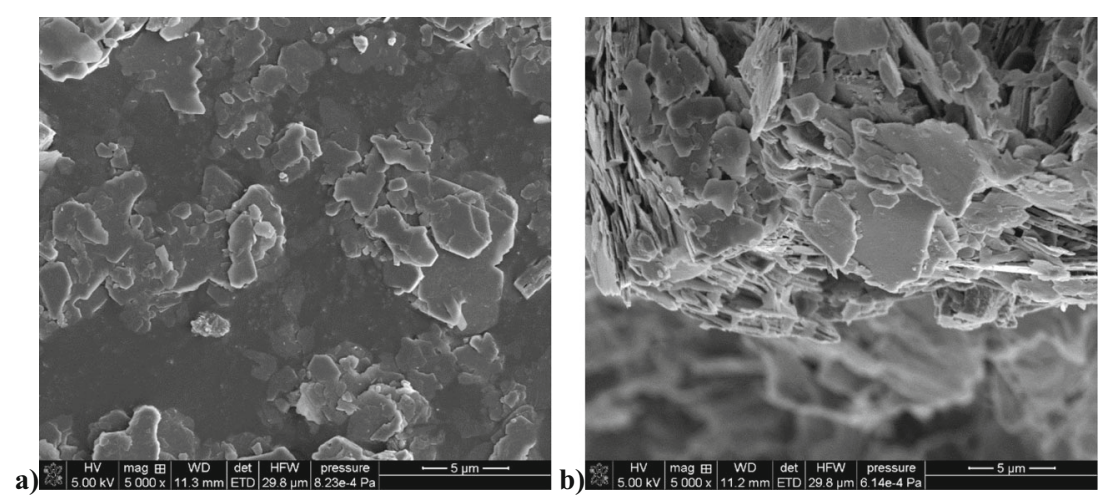

(7) The $\mathrm{Cr}(\mathrm{VI})$ ions are successfully immobilized and reduced in the soil mineral/cationic polyacrylamide system, which limits considerably this heavy metal availability for plants.

\section{Compliance with ethical standards}

Conflict of interest The authors declare that they have no conflict of interest.

Ethical approval The research did not involve human participants and/ or animals.

Open Access This article is licensed under a Creative Commons Attribution 4.0 International License, which permits use, sharing, adaptation, distribution and reproduction in any medium or format, as long as you give appropriate credit to the original author(s) and the source, provide a link to the Creative Commons licence, and indicate if changes were made. The images or other third party material in this article are included in the article's Creative Commons licence, unless indicated otherwise in a credit line to the material. If material is not included in the article's Creative Commons licence and your intended use is not permitted by statutory regulation or exceeds the permitted use, you will need to obtain permission directly from the copyright holder. To view a copy of this licence, visit http://creativecommons.org/licenses/by/4.0/.

\section{References}

Alkorta I, Hernandez-Allica J, Becerril JM, Amezaga I, Albizu I, Gabisu C (2004) Recent findings on the phytoremediation of soils contaminated with environmentally toxic heavy metals and metalloids such as zinc, cadmium, lead and arsenic. Rev Environ Sci Biotechnol 3: 71-90

Al-Mashqbeha A, Abualia S, El-Eswedb B, Khalilia FI (2018) Immobilization of toxic inorganic anions $\left(\mathrm{Cr}_{2} \mathrm{O}_{7}{ }^{2-}, \mathrm{MnO}_{4}{ }^{-}\right.$and $\left.\mathrm{Fe}(\mathrm{CN})_{6}{ }^{3-}\right)$ in metakaolin based geopolymers: a preliminary study. Ceram Int 44:5613-5620

Ashworth DJ, Alloway BJ (2004) Soil mobility of sewage sludge-derived dissolved organic matter, copper, nickel and zinc. Environ Pollut 127:137-144

Bich C, Ambroise J, Péra J (2009) Influence of degree of dehidroxylation on the pozzolanic activity of metakaolin. Appl Clay Sci 44:194-200

Borymski S, Piotrowska-Seget Z (2014) Rhizosphere of metallophytes and its role in bioremediation of heavy metals. Chemik 68:554-559
Cao X, Ma LQ, Shiralipour A (2003) Effects of compost and phosphate amendments on arsenic mobility in soils and arsenic uptake by the hyperaccumulator, Pteris vittata L. Environ Pollut 126:157-167

Choppala G, Bolan N, Kunhikrishnan A, Skinner W, Seshadri B (2015) Concomitant reduction and immobilization of chromium in relation to its bioavailability in soils. Environ Sci Pollut Res 22:8969-8978

Dhal B, Thatoi H, Das N, Pandey B (2013) Chemical and microbial remediation of hexavalent chromium from contaminated soil and mining/metallurgical solid waste: a review. J Hazard Mater 250: 272-291

Fan TT, Wang YJ, Li CB, Zhou DM, Friedman SP (2015) Effects of soil organic matter on sorption of metal ions on soil clay particles. Soil Sci Soc Am J 79:794-802

Fijałkowski K, Kacprzak M, Grobelak A, Placek A (2012) The influence of selected soil parameters on the mobility of heavy metals in soil. Inżynieria i Ochrona Środowiska 15:81-92

Foo KY, Hameed BH (2010) Insights into the modeling of adsorption isotherm systems. Chem Eng J 156:2-10

Ford KLI, Neuman D (2006) Phytostabilization as a remediation alternative at mining sites. Technical Note 420:2-48

Gardner M, Comber S (2002) Determination of trace concentrations of hexavalent chromium. Analyst 127:153-156

Gild M, Sobrados I, Rhaiem HB, Sanz J, Amara ABH (2017) Alkaline activation of metakaolinite-silica mixtures: Role of dissolved silica concentration on the formation of geopolymers. Ceram Int 43: $12641-12650$

Hazrat A, Khan E, Muhammad AS (2013) Phytoremediation of heavy metals-Concepts and applications. Chemosphere 91:869-881

Hedberg YS, Lidén C, Wallinder IO (2014) Correlation between bulkand surface chemistry of Cr-tanned leatherand the release of $\mathrm{Cr}(\mathrm{III})$ and Cr(VI). J Hazard Mater 280:654-661

Ho YS, McKay G (1998) Sorption of dye from aqueous solution by peat. Chem Eng J 70:115-124

Ho YS, McKay G (2002) Application of kinetics models to the sorption of copper(II) onto peat. Adsorpt Sci Technol 20:797-815

Janusz W (1994) Electrical double layer at the metal oxide/electrolyte interface in interfacial forces and fields: theory and applications. In: Decker, M. (ed.), Surfactant science, vol. 85. Chapter 4, New York

Kilic E, Puig R, Baquero G, Font J, Colak S, Guerler D (2011) Environmental optimization of chromium recovery from tannery sludge using a life cycle assessment approach. J Hazard Mater 192:393-401

Kwiatkowska-Malina J, Maciejewska A (2012) Activity in soils contaminated by heavy metals. Soil Sci Annu 63(1):39-41

McLaughlin MJ, Zarcinas BA, Stevens DP, Cook N (2000) Soil testing for heavy metals. Commun Soil Sci Plant Anal 31(11-14):16611700 
Ndlovu B, Farrokhpay S, Forbes E, Bradshaw D (2015) Characterisation of kaolinite colloidal and flow behavior via crystallinity measurements. Powder Technol 269:505-512

Ogundiran MB, Winjobi FA (2015) The potential of binary blended geopolymer binder containing Ijero-Ekiti calcuned kaolin clay and ground waste window glass. Afr J Pure Appl Chem 9:159-166

Ohshima H (1994) A simple expression for Henry's function for the retardation effect in electrophoresis of spherical colloidal particles. J Colloid Interface Sci 168:269-271

Ościk J (1969) Adsorption (in Polish). UMCS, Lublin

Roth E, Mancier V, Fabre B (2012) Adsorption of cadmium on different granulometric soil fractions: influence of organic matter and temperature. Geoderma 189-190:133-143

Shi C, Fernandez-Jimenez A (2006) Stabilization/solidification of hazardous and radioactive wastes with alkali-activated cements. J Hazard Mater 137:1656-1663

Singh R, Misra V, Singh RP (2012) Removal of Cr(VI) by Nanoscale zero-valent iron (nZVI) from soil contaminated with tannery wastes. Bull Environ Contam Toxicol 88:210-214

Tironi A, Trezza MA, Irassar EF, Scian AN (2012) Thermal treatment of kaolin: effect on the pozzolanic activity. In: 11th International Congress on Metallurgy \& Materials SAM/CONAMET 2011. Procedia Mater Sci 1:343-350

Vinutha M, Naika HSN, Manjanna J (2015) Remediation of hexavalent chromium from aqueous solution usingclay mineral Fe(II)-montmorillonite: encompassing anion exclusion impact. Appl Surf Sci 357:1244-1250

Wang H, Zhou A, Peng F, Yu H, Yang J (2007) Mechanism study on adsorption of acidified multiwalled carbon nanotubes to $\mathrm{Pb}(\mathrm{II})$. J Colloid Interface Sci 316:277-283
Weng CH, Huang CP, Sanders PF (2002) Transport of Cr (VI) in soils contaminated with chromite ore processing residue (COPR). Pract Period Hazard Toxic Radioactive Waste Manage 6:6-13

Weng CH, Sharma YC, Chu SH (2008) Adsorption of Cr(VI) from aqueous solutions by spent activated clay. J Hazard Mater 155(1-2):6575

Wiśniewska M, Chibowski S, Urban T (2014a) Effect of the presence of cationic polyacrylamide on the surface properties of aqueous alumina suspension - stability mechanism. Appl Surf Sci 320:843-851

Wiśniewska M, Chibowski S, Urban T (2014b) Impact of polyacrylamide with different contents of carboxyl groups on the chromium(III) oxide adsorption properties in aqueous solution. J Hazard Mater 283:815-823

Wiśniewska M, Chibowski S, Urban T (2017) Comparison of adsorption affinity of ionic polyacrylamide for the surfaces of selected metal oxides. Adsorpt Sci Technol 35:582-591

Wiśniewska M, Chibowski S, Urban T, Terpiłowski K (2019) Investigation of chromium(III) oxide removal from the aqueous suspension using the mixed flocculant composed of anionic and cationic polyacrylamides. J Hazard Mater 368:378-385

Xiao A, Ouyang Y, Li WC, Ye Z (2017) Effect of organic manure on Cd and As accumulation in brown rice and grain yield in Cd-Ascontaminated paddy fields. Environ Sci Pollut Res 24:9111-9121

Yukselen-Aksoy Y, Kaya A (2003) Zeta Potential of kaolinite in the presence of alkali, alkaline Earth and hydrolyzable metal ions. Water Air Soil Pollut 145(1):155-168

Publisher's note Springer Nature remains neutral with regard to jurisdictional claims in published maps and institutional affiliations. 